\title{
EFFECT OF TENSILE DEFORMATION ON AUSTENITIC Cr - Ni-STEEL STRUCTURE AND MAGNETIC PROPERTIES
}

\author{
L. A. Mal'tseva ${ }^{1}$ and S. Yu. Mitropol'skaya ${ }^{1,2}$
}

Translated from Metallovedenie i Termicheskaya Obrabotka Metallov, No. 6, pp. 43 - 49, June, 2013.

\begin{abstract}
Deformation metastability of chromium-nickel steels of austenitic and austenitic-ferritic classes is studied directly during specimen extension in a magnetic measurement facility. Structural changes and their correlation with steel magnetic properties are analyzed.
\end{abstract}

Key words: austenite, $\delta$-ferrite, strain induced martensite, coercive force, maximum magnetization, field dependence of differential magnetic permeability, tensile plastic deformation, strength.

\section{INTRODUCTION}

A disadvantage of austenitic steels is the relatively low yield and ultimate breaking strengths in a quenched condition. In view of this steel after hardening is given cold plastic deformation by drawing and/or flattening, which makes it possible not only to obtain a prescribed standard size, but also to increase strength properties significantly. However, not all austenitic steels exhibit good ductility and workability. On the basis of comprehensive research new chromium-nickel steels have been smelted, additionally alloyed with $\mathrm{Co}$, Mo. $\mathrm{Ti}$, and $\mathrm{Al}$ [1], intended for preparing highstrength wire strip of thin and very thin cross sections. It is well known [2] that cobalt in austenitic steels acts similarly to manganese: it reduces packing defect energy and promotes occurrence of $\gamma \rightarrow \varepsilon$-transformation. As a result of this alloying with cobalt does not affect structure formation and steel properties with cold plastic deformation by drawing. Aluminum, as a strong ferrite forming element, leads to preparation of steels of the austenitic-ferritic class with a different ratio of austenite and $\delta$-ferrite.

All of the steels studied in this work are practically carbon-free; the carbon content ${ }^{3}$ did not exceed $0.03 \%$. Variation of the amount of $\mathrm{Cr}$ and $\mathrm{Ni}$, and an increase in proportion of $\mathrm{Al}$ from $0.8 \%$ to $2.5 \%$ provided a possibility of converting steels into different structural classes in a sequence:

1 B. N. El'tsin Ural Federal University, Ekaterinberg, Russia (e-mail:mla44@mail.ru).

2 Engineering Institute, Ural Branch of the Russian Academy of Sciencies, Ekaterinburg, Russia.

3 Here and subsequently the content of elements is given in weight fraction, expressed as a $\%$. austenitic $\rightarrow$ austenitic-ferritic. Austenitic-ferritic steels, compared with austenitic steels, have increased yield strength, good weldability, corrosion resistance, and are used quite extensively in industry and are interesting for further research [3].

One of the main methods for studying metastable austenitic steels over many decades has been magnetic analysis [4]. Use of contemporary magnetic measuring units combined with mechanical tests makes it possible to detect features in deformation behavior of austenitic steels, previously evading the attention of researchers in view of inadequate equipment. An important example of additional extraction of useful information from results of magnetic measurements is analysis of the field dependence of differential magnetic permeability [5].

The aim of this work is to study deformation metastability of austenitic and austenitic-ferritic class steels directly during specimen extension in magnetic-measuring unit, which to some extent simulates operation of billet cold drawing.

\section{METHODS OF STUDY}

Three melts of chromium - nickel steels were studied, differing in cobalt and aluminum content. Melting of ingots weighing $10-20 \mathrm{~kg}$ was performed in open type induction furnaces. Commercial purity components were used in order to prepare charges. Two ingots of steels $03 \mathrm{Kh} 14 \mathrm{~N} 11 \mathrm{~K} 5 \mathrm{M} 2 \mathrm{YuT}$, 03Kh14N11KM2YuT, 03Kh14N10K5M2Yu2T were melted. Melt chemical composition is provided in Table 1.

After homogenizing annealing at $1160^{\circ} \mathrm{C}$ for $10 \mathrm{~h}$ and mechanical cleaning of ingots they were forged and turned to 
TABLE 1. Steel Chemical Composition

\begin{tabular}{lccccccccc}
\hline & \multicolumn{1}{c}{ Element content, wt.\% } \\
\cline { 2 - 9 } Steel & $\mathrm{C}$ & $\mathrm{Si}$ & $\mathrm{Mn}$ & $\mathrm{Cr}$ & $\mathrm{Ni}$ & $\mathrm{Mo}$ & $\mathrm{Co}$ & $\mathrm{Ti}$ & $\mathrm{Al}$ \\
\hline 03Kh14N11K5M2YuT (melt 4) & $\leq 0.03$ & 0.21 & 0.19 & 14.5 & 11.15 & 2.5 & 5.1 & 0.30 & 0.80 \\
03Kh14N11KM2YuT (melt 5) & $\leq 0.03$ & 0.30 & 0.08 & 14.7 & 10.52 & 2.7 & 0.7 & 0.36 & 0.98 \\
03Kh14N10K5M2Yu2T (melt 6) & $\leq 0.03$ & 0.20 & 0.07 & 14.3 & 10.40 & 2.6 & 5.1 & 0.80 & 2.00 \\
\hline
\end{tabular}

Note. 1. Melt conditional number given in brackets.

2. All test steels contained not more than $0.025 \% \mathrm{~S}$ and $\mathrm{P}$ each.

TABLE 2. Test Steel Phase Composition, Mechanical and Magnetic Properties

\begin{tabular}{|c|c|c|c|c|c|c|c|c|c|}
\hline \multirow{2}{*}{ Melt } & \multicolumn{2}{|c|}{ Phase composition, $\%$} & \multirow{2}{*}{$\sigma_{\mathrm{r}}, \mathrm{MPa}$} & \multirow{2}{*}{$\sigma_{0.2}, \mathrm{MPa}$} & \multirow{2}{*}{$\delta, \%$} & \multirow{2}{*}{$\psi, \%$} & \multirow{2}{*}{$H V_{50}, \mathrm{kgf} / \mathrm{mm}^{2}$} & \multirow{2}{*}{$\mu_{0} M_{\max }, \mathrm{T}$} & \multirow{2}{*}{$H_{c}, \mathrm{kA} / \mathrm{m}$} \\
\hline & Ferrite & Austenite & & & & & & & \\
\hline 4 & - & $\sim 100$ & 540 & 245 & 63 & 83 & $-/ 210$ & $<0.001$ & 7.42 \\
\hline 5 & 10 & 90 & 580 & 340 & 53 & 78 & $-/ \sim 210$ & 0.008 & 3.55 \\
\hline 6 & 50 & 50 & 940 & 730 & 24 & 73 & $505 / 190$ & 0.600 & 1.77 \\
\hline
\end{tabular}

Note. Ferrite microhardness is given in the numerator and for austenite in the denominator.

a diameter of $14 \mathrm{~mm}$. Ten-fold cylindrical specimens were prepared from billets obtained in accordance with GOST 1497 with a gauge length diameter of $7 \mathrm{~mm}$ for tensile tests with simultaneous measurement of magnetic properties. Specimens were water quenched from $1000^{\circ} \mathrm{C}$ for supersaturated $\gamma$ - or $(\gamma+\delta)$-solid solutions.

The effect of uniaxial tension on magnetic properties was studied at room temperature in a test machine with a maximum force of $50 \mathrm{kN}$ with active grip movement at a rate of $1 \mathrm{~mm} / \mathrm{min}$. Magnetic properties were measured in a closed magnetic circuit by a permeameter scheme using a Remagrah C-500 hysteresisgraph, during which loading was suspended. All magnetic measurements were carried out before neck formation in a specimen. The magnetic field was applied along the long specimen axis, before the start of each magnetic measurement and for the end of specimen magnetization. Magnetic hysteresis loops recorded were calculated taking account of the reduction in specimen cross section during extension. Field dependences of differential magnetic permeability $\mu_{d}$, determined by an expression

$$
\mu_{d}=\lim _{\Delta H \rightarrow 0} \frac{\Delta \mu_{0} M}{\Delta H}=\frac{\mathrm{d} \mu_{0} M}{\mathrm{~d} H},
$$

were obtained by means of three-point differentiation of descending branches of limiting loops in the range from +60 to $-60 \mathrm{kA} / \mathrm{m}$. In addition, coercive force $H_{c}$, residual induction $B_{r}$, and magnetization $\mu_{0} M_{\max }$ were evaluated with the maximum internal magnetic field intensity $H_{\max }=60 \mathrm{kA} / \mathrm{m}$. Measurement error did not exceed 3\% for both magnetization and the magnetic field magnitude. The confidence range for values obtained for differential magnetic permeability with a confidence level of 0.95 did not exceed 0.04 .

Steel structure was studied in a TESCAN scanning electron microscope. Phase composition was evaluated by means of x-ray structural analysis.

\section{RESULTS AND DISCUSSION}

The phase composition of test steels is provided in Table 2. It is seen that variation of cobalt and aluminum content makes it possible to obtain a different steel condition after quenching: austenitic (melts 4 and 5 ) and austenitic-ferritic (melt 6 ). Comparison of Tables 1 and 2 shows that alloying with cobalt in an amount of about $5.0 \%$ leads to suppression of $\delta$-ferrite formation (melt 4 ), whereas in steel with a reduced cobalt content (melt 5 ) after quenching up to $10 \%$ $\delta$-ferrite is observed. The microstructure of melts 4 and 5 is normal for austenitic steels, and contains grains of polyhedral shape with a large number of annealing twins (Fig. $1 a$ and $b$ ).

Quenched steel 03Kh14N10K5M2Yu2T (melt 6) has a structure consisting of two main phases, i.e. austenite and $\delta$-ferrite in approximately equal amounts (Fig. 1c, Table 2), and it has a higher yield strength than melts 4 and 5 (Table 2). The microhardness of $\delta$-ferrite within the structure of melt 6 is anomalously high (of the order of $500 \mathrm{HV}$ ), whereas the microhardness of austenite is within the limits of $200 \mathrm{HV}$. Presence of a two-phase structure, consisting of phases of different hardness, is an important condition for quite good ductility of hardened austenitic-ferritic steels. 

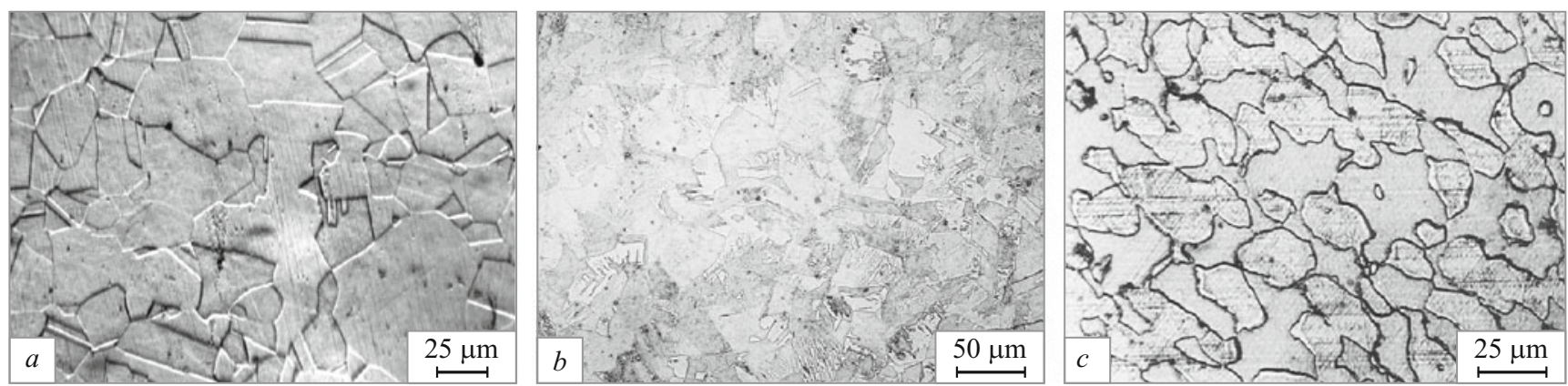

Fig. 1. Microstructure of steels quenched from $\left.1000^{\circ} \mathrm{C}: a\right) 03 \mathrm{Kh} 14 \mathrm{~N} 11 \mathrm{~K} 5 \mathrm{M} 2 \mathrm{YuT}($ melt 4 ); $b$ ) $03 \mathrm{Kh} 14 \mathrm{~N} 11 \mathrm{KM} 2 \mathrm{YuT}$ (melt 5 ); $c$ ) 03Kh14N10K5M2Yu2T (melt 6 ).

The value of magnetization with a maximum internal field magnetic for steels in a quenched condition is determined mainly by the amount of $\delta$-ferrite, which forms as a result of heat treatment: $\mu_{0} M_{\max } \approx 0.008$ and $0.6 \mathrm{~T}$ respec- tively with $10 \% \delta$-ferrite, and about equal fractions of austenite and $\delta$-ferrite (Table 2). Presence of a considerable amount of austenite within the structure acts as a powerful magnetization factor and gives steels a high coercive force.
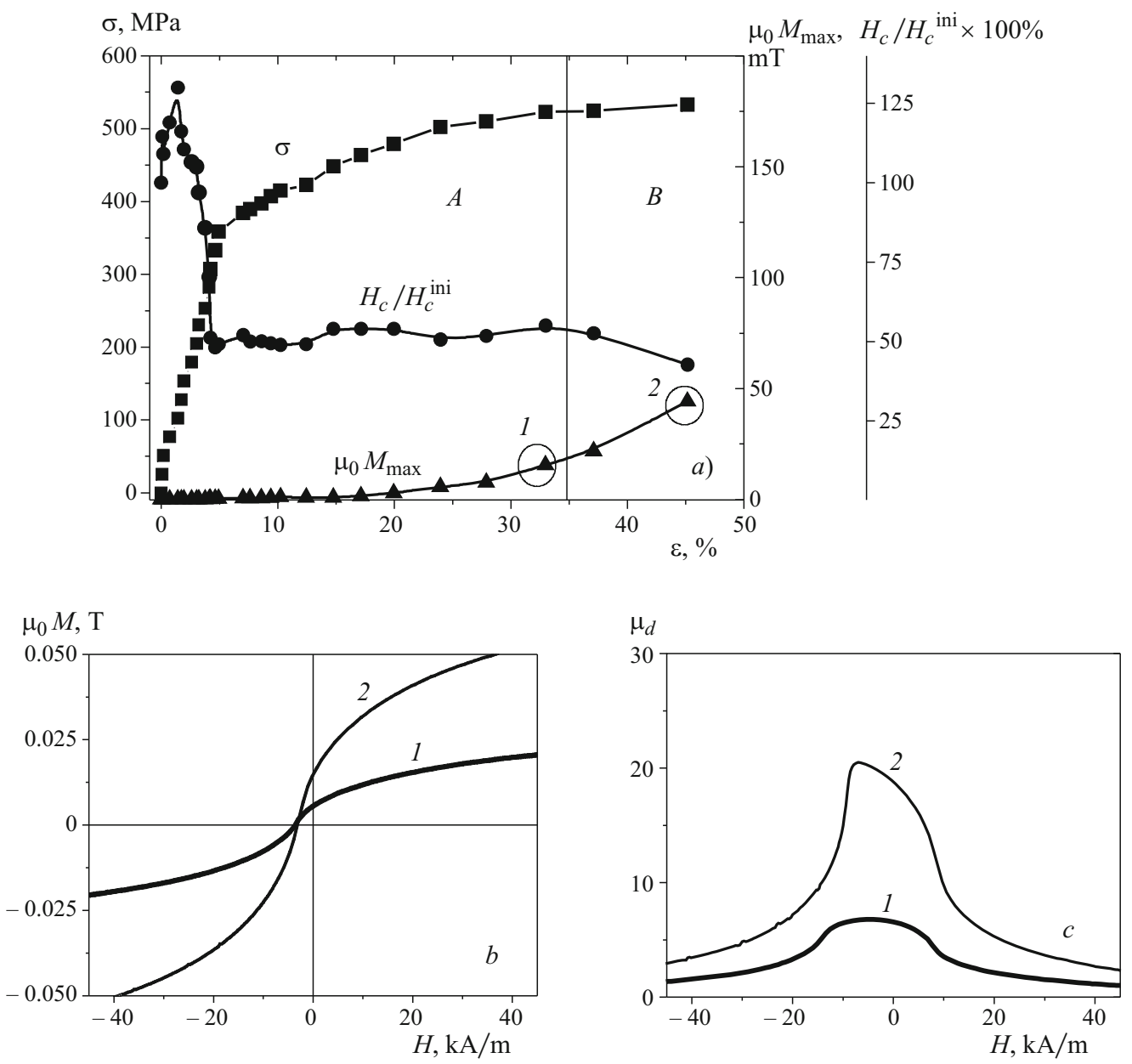

Fig. 2. Change in steel $03 \mathrm{Kh} 14 \mathrm{~N} 11 \mathrm{~K} 5 \mathrm{M} 2 \mathrm{YuT}$ (melt 4 ) magnetic properties during uniaxial tension: $a$ ) $\sigma$ is stress, $\varepsilon$ is degree of deformation, $H_{c}$ is coercive force, $\mu_{0} M_{\max }$ is maximum magnetization; $b, c$ ) respectively magnetic hysteresis half-loops and field dependence of differential magnetic permeability $\mu_{d}(H)$ at points on the curve $\mu_{0} M_{\max }(\varepsilon)$ marked with circles. 

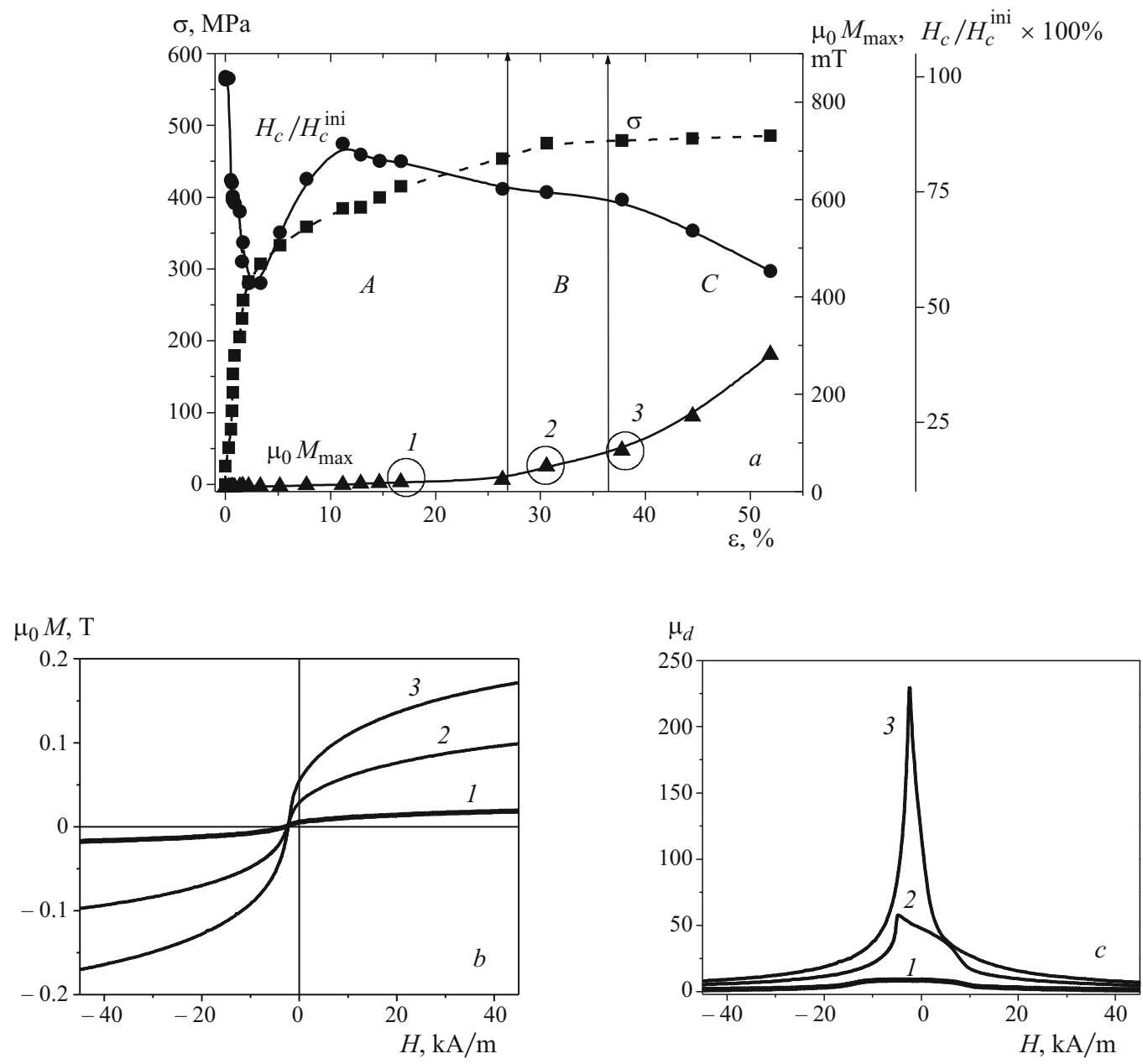

Fig. 3. Change in steel 03Kh14N11KM2YuT (melt 5 ) magnetic properties during uniaxial tension (for labelling see Fig. 2).

Extension of specimens in a magnetic-measurement unit to some extent simulates operation of cold billet drawing, since in this case there is deformation by extension in one axis and deformation by compression in radial axes. Stress strain curves provided in Figs. $2 a, 3 a$, and $4 a$ indicate that cold plastic deformation promotes marked test steel strengthening. The nature of change in magnetic properties under the action of deformation makes it possible to determine by which physical mechanisms this strengthening occurs.

Comparison of $\sigma(\varepsilon)$ and $\mu_{0} M_{\max }(\varepsilon)$ curves in Fig. $2 a$ shows the contribution of deformation $\gamma \rightarrow \alpha$-transformation to strengthening steel $03 \mathrm{Kh} 14 \mathrm{~N} 11 \mathrm{~K} 5 \mathrm{M} 2 \mathrm{YuT}$ (melt 4 ) is extremely small: a weak increase in magnetization $\mu_{0} M_{\max }$ (to $50 \mathrm{mT}$ ) is only observed in the stage of developed plastic deformation, when the relative elongation exceeds $25 \%$, and the deforming stress hardly increases. It may be suggested that the main contribution to material strengthening in the early stages of extension is work hardening, and an increase in $\gamma$-solid solution defectiveness, and also occurrence of $\gamma \rightarrow \varepsilon$-transformation, the tendency towards which, due to a reduction in packing defect energy, is provided by a high (up to $5 \%$ ) cobalt content [2].

Steel 03Kh14N11KM2YuT (melt 5 ) due to a reduced cobalt content has a higher tendency towards deformation $\gamma \rightarrow \alpha$-transformation than steel 03Kh14N11K5M2YuT (melt 4 ): magnetization in a maximum field at the instant of forming a neck $\mu_{0} M_{\max }=250$ and $45 \mathrm{mT}$ respectively. Analysis of $\sigma(\varepsilon)$ and $\mu_{0} M_{\max }(\varepsilon)$ curves in Fig. $3 a$ shows that the contribution of deformation to $\gamma \rightarrow \alpha$-transformation to steel 03Kh14N11K5M2YuT strengthening is also small and does not reduce material ductility in the uniform elongation stage. In melt 5 the main deformation strengthening also occurs in the early stages of deformation, i.e., with $\varepsilon \leq 25 \%$ (Fig. $3 a$ ). A marked increase in coercive force $H_{c}$ in the deformation range $3 \%<\varepsilon<12 \%$ points to marked work hardening and strengthening of $\delta$-ferrite structure defects, which in this stage remains a ferromagnetic phase, determining steel hysteresis properties. It should be noted that in the elastic region of tension a reduction in $H_{c}$ is approximately $45 \%$ of the original value for melt 5 (Fig. $3 a$ ), as also for melt 6 

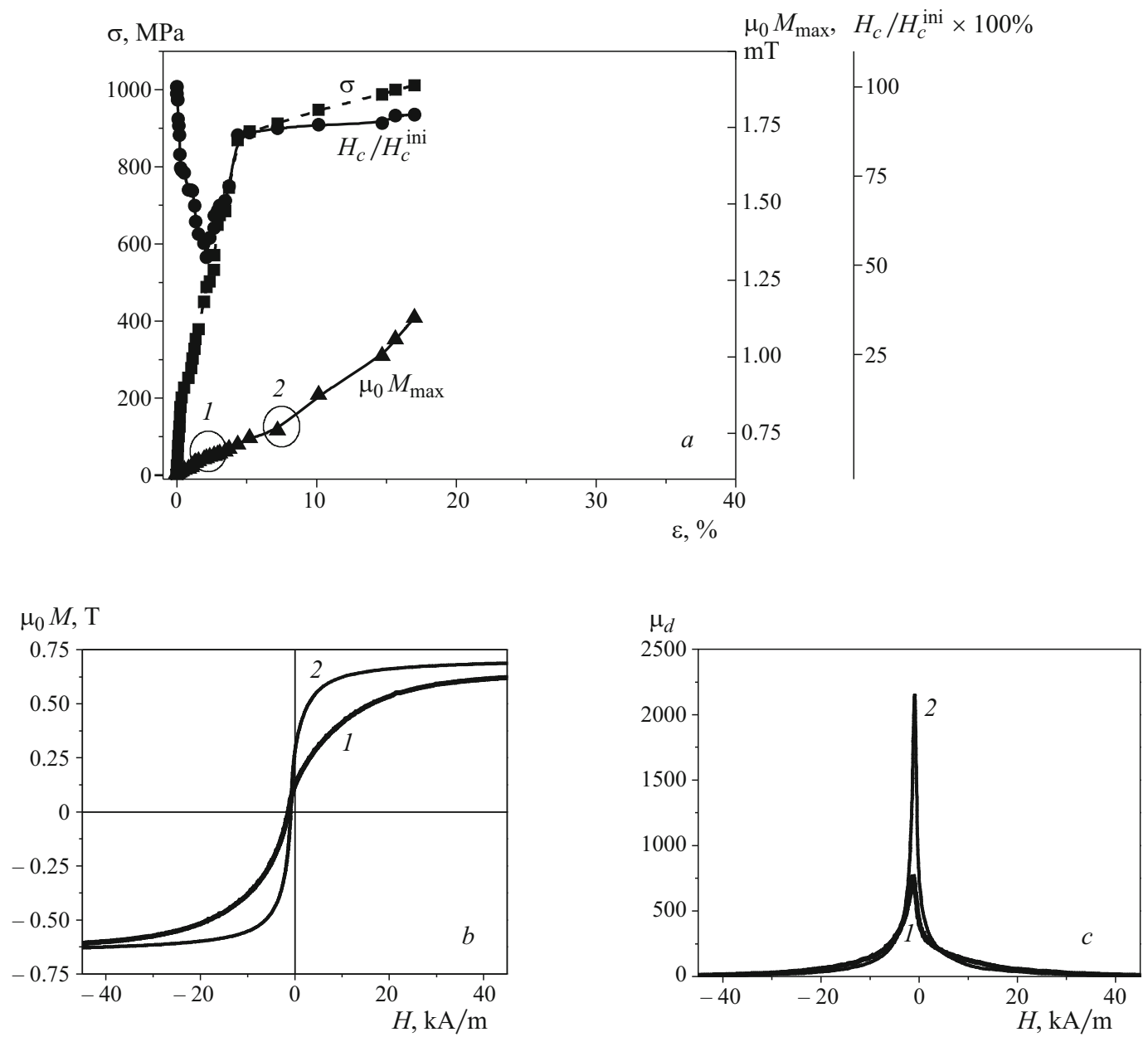

Fig. 4. Change in steel $03 \mathrm{Kh} 14 \mathrm{~N} 10 \mathrm{~K} 5 \mathrm{M} 2 \mathrm{Yu} 2 \mathrm{~T}$ (melt 6 ) magnetic properties during uniaxial tension (for labelling see Fig. 2).

(Fig. $4 a$ ), caused by a magnetic elastic effect, which has been described in detail in publications for ferritic and ferritic-pearlitic steels [6-8].

For steel 03Kh14N10K5M2Yu2T (melt 6) on a background of significant strengthening $\left(\sigma_{0.2}=730 \mathrm{MPa}, \sigma_{\mathrm{r}}=\right.$ $940 \mathrm{MPa}$ ) there is a typical sharp reduction in ductility and high tendency towards early strain localization (Fig. $4 a$ ): the start of neck formation is recorded with relative elongation of $19 \%$. This nature of deformation behavior for steel is caused not only by high $(50 \%) \delta$-ferrite content, whose hardness is higher by a factor of 2.5 than for austenite (Table 2), but also by intense $\gamma \rightarrow \alpha$-transformation, and this is indicated by an increase in magnetization $\mu_{0} M_{\max }$ from $0.6 \mathrm{~T}$ in the original condition to about $1.2 \mathrm{~T}$ at the start of neck formation. In the elastic region there is a reduction in coercive force $H_{c}$, which ceases with transition from a macroelastic to microplastic deformation. An almost stable value of coercive force $H_{c}$ in the stage of deformation strengthening of steel 03Kh14N10K5M2Yu2T (Fig. $4 a$ ) reflects presence of at least two competing processes: 1 ) a reduction in the proportion of austenite from 50 to $10 \%$ should lead to a reduction in coercive force due to a reduction in the magnetization factor, connected with dissipation fields; 2) formation of magnetically hard structural component, i.e., strain induced $\alpha$-martensite, as also $\delta$-ferrite work hardening, should cause an increase in coercive force.

Analysis of the shape of the magnetic hysteresis loop and those obtained on the basis of field dependences of differential magnetic permeability made it possible in addition to extract useful information from the results of magnetic measurements, combined with tensile tests. In spite of the significant difference in mechanical properties and phase stability of the steels studied, all recorded magnetic hysteresis loops and field dependences $\mu_{d}(H)$ corresponding to them could be separated into three types:

1) a flat magnetic hysteresis loop (curve 1 in Figs. $2 b$ and $3 b)$ and a blurred maximum for the dependence $\mu_{d}(H)$ (curve 1 in Figs. $2 c$ and $3 c$ );

2) a "steeper" magnetic hysteresis loop, containing inflections (curve 2 in Figs. $2 b$ and $3 b$ ), which with differentiation gives a clear asymmetric magnetic permeability peak (curve 2 in Figs. $2 c$ and $3 c$ ); 

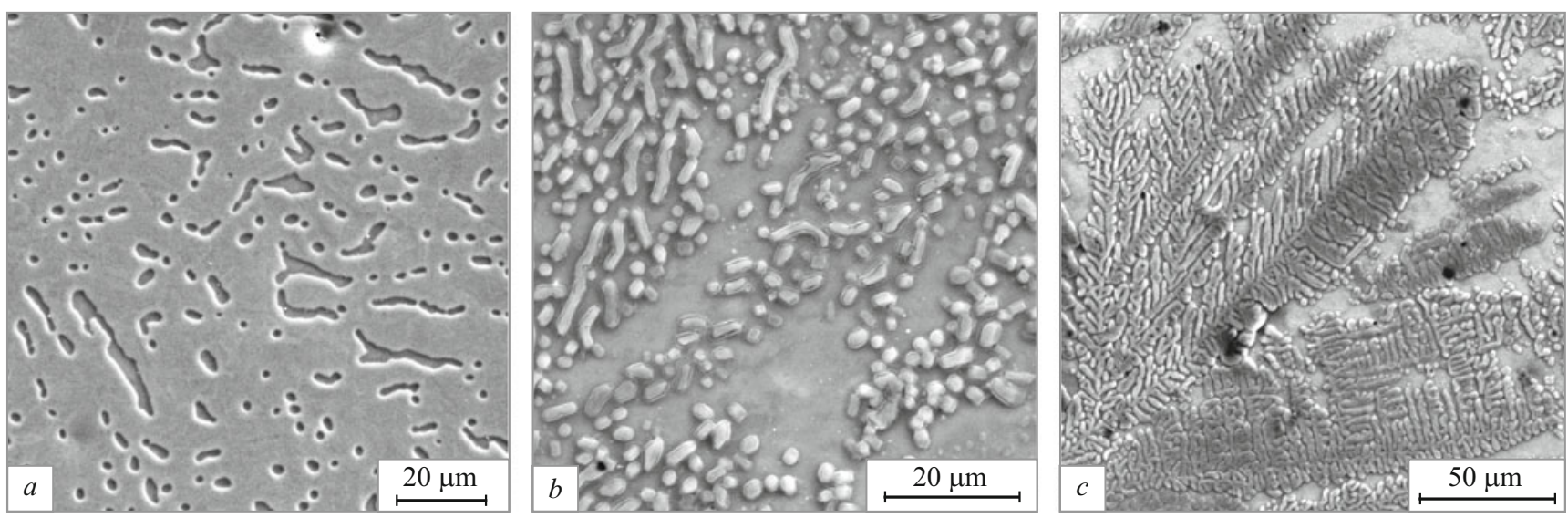

Fig. 5. Evolution of steel 03Kh14N11KM2YuT (melt 5 ) structure under the action of tension: $a, b, c$ ) stages $A, B, C$ respectively.

3 ) hysteresis loops normal for ferromagnetic materials (curve 3 in Fig. $3 b$ and curves 1, 2 in Fig. $4 b$ ) and symmetrical magnetic permeability peaks (curve 3 in Fig. $3 c$ and curves 1 and 2 in Fig. $4 c$ ).

The successive evolution of the magnetic hysteresis loops recorded and field dependences $\mu_{d}(H)$ under the action of tension made it possible to separate stages on stressstrain curves corresponding to them. With tension for steel 03Kh14N11K5M2YuT (melt 4) first type magnetic permeability peaks are observed with a degree of deformation $\varepsilon$ up to about $35 \%$, after which there are second type peaks, which are recorded up to neck formation (Fig. $2 a$, regions $A$ and $B$ respectively). For steel 03Kh14N11KM2YuT (melt 5 ) there is typically successive change of three types of field dependences $\mu_{d}(H)$, and it is possible to break down the strengthening curve into three stages (Fig. $3 a): A(\varepsilon<30 \%)$, $B(30 \% \leq \varepsilon<37 \%)$, and $C(\varepsilon>37 \%)$. Loops and field dependences $\mu_{d}(H)$ for steel 03Kh14N10K5M2Yu2T (melt 6 ) in the original condition have a form typical for ferromagnetic materials, as a result of high $\delta$-ferrite content.

Microstructural studies of specimens, selected for the elongation route in stages $A, B$, and $C$ made it possible to connect the magnetic behavior features observed with steel structural properties. The structure of steel 03Kh14N11KM2YuT (melt 5 ) is given in Fig. 5, most typical for the three stages described: in stage $A$ this is a two-phase structure of austenite $+\delta$-ferrite (Fig. $5 a$ ); in stage $B$ additionally isolated anisotropic crystals of $\alpha$-martensite appear (Fig. $5 b$ ), which are apparently remagnetized as a single-domain [9]; in stage $C$ $\alpha$-martensite crystals acquire the form of closed structural complexes of the "carcase" type (Fig. 5c), which are remagnetized as an assembly of interacting particles, and this leads to loss of asymmetry in magnetic permeability peaks.

It is important to note that typical asymmetric peaks in the dependences $\mu_{d}(H)$ were only observed in those cases when in the original condition the $\delta$-ferrite content did not exceed $10 \%$. In two-phase $(\gamma+\delta)$ melt 6 the contribution from massive and numerous $\delta$-ferrite grains overlaps the contribution from $\alpha$-martensite crystals in forming hysteresis properties. As a result of this in field dependences $\mu_{d}(H)$ there are only symmetrical peaks.

\section{CONCLUSIONS}

1. Chromium-nickel steels of austenitic and austeniticferritic classes exhibit different degrees of austenite metastability and inclination to $\gamma \rightarrow \varepsilon \rightarrow \alpha-$ and $\gamma \rightarrow \alpha$-transformations. Alloying with cobalt suppresses formation of $\delta$-ferrite in austenitic steels.

2. Analysis of the field dependence of differential magnetic permeability $\mu_{d}(H)$ makes it possible to reveal the stages of $\mu_{d}(H)$ function evolution with tension for steels, caused by morphological features of strain induced $\alpha$-martensite; separation of isolated fine particles leads to appearance of a clearly asymmetric peak in the field dependence $\mu_{d}(H)$; further development of deformation $\gamma \rightarrow \alpha$-transformation with formation of complexes of the carcase type from $\alpha$-martensite crystals is accompanied by substitution of asymmetric peaks by symmetric peaks.

3. The magnetic effects detected in steels with different deformation austenite stability may be useful for diagnosing small deformation-induced changes in austenitic steels with unknown original magnetization, and also open up the possibility for spontaneous derivation of operation of those structural elements, within which martensitic transformation proceeded excessively rapidly.

\section{REFERENCES}

1. L. A. Mal'tseva, N. N. Ozerets, I. I. Kositsyna, et al., "Study of structure formation for metastable austenitic steel 03Kh14N10K5M2Yu2T with deformation action," Metalloved. Term. Obrab. Met., No. 10, $14-18$ (2008).

2. L. A. Mal'tseva, S. M. Zadvorkin, V. A. Sharapova, et al., "Role of cobalt in structure formation and physicomechanical proper- 
ties of metastable austenitic steels after different elastoplastic deformation," Deform. Razrush. Mater., No. 5, 23 - 31 (2012).

3. L. A. Mal'tseva, "Structure and strength properties of corrosionresistant austenite-ferrite steel for medicinal purposes after thermoplastic deformation," Deform. Razrush. Mater., No. 1, $1-8$ (2010).

4. I. N. Bogachev and V. F. Egolaev, Structure and Properties of Iron-Manganese Alloys [in Russian], Metallurgiya, Moscow (1973).

5. S. Yu. Mitropol'skaya, "Effect of tensile stresses on magnetic properties of austenitic steel with $0.4 \%$ nitrogen," Vopr. Materialoved., No. 3, 393 (2010).
6. V. K. Babich and V. A. Pirogov, "Nature of change in coercive force with deformation of annealed carbon steels, Fiz. Met. Metalloved., 28(3), 447 - 453 (1969).

7. V. F. Novikov and V. A. Izosimov, "Effect of elastic stresses on coercive force," Fiz. Met. Metalloved., 58(2), 275 - 281 (1984).

8. G. V. Bida and V. G. Kuleev, "Effect of elastic deformation on magnetic properties of steel with different structure," Defektoskopiya, No. 11, 12 - 26 (1998).

9. É. S. Gorkunov, S. M. Zadvorkin, S. Yu. Mitropol'skii, et al., "Change in magnetic properties of metastable austenitic steel with elastoplastic deformation," Metalloved. Term. Obrab. Met., No. 9, 15 - 21 (2009). 